Check for updates

Cite this: Phys. Chem. Chem. Phys., 2018, 20, 27185

Received 17th July 2018 Accepted 12th October 2018

DOI: $10.1039 / c 8 c p 04525 a$

rsc.li/pccp

\title{
Strong enrichment of atmospherically relevant organic ions at the aqueous interface: the role of ion pairing and cooperative effects $\dagger$
}

\author{
Victor Ekholm, (D)*a Carl Caleman, (D) ab Nicklas Bjärnhall Prytz, ${ }^{c}$ \\ Marie-Madeleine Walz, (D) J Josephina Werner, (D) ${ }^{a}$ Gunnar Öhrwall, (D) \\ Jan-Erik Rubensson ${ }^{a}$ and Olle Björneholm ${ }^{a}$
}

\begin{abstract}
Surface affinity, orientation and ion pairing are investigated in mixed and single solute systems of aqueous sodium hexanoate and hexylammonium chloride. The surface sensitive $\mathrm{X}$-ray photoelectron spectroscopy technique has been used to acquire the experimental results, while the computational data have been calculated using molecular dynamics simulations. By comparing the single solute solutions with the mixed one, we observe a non-linear surface enrichment and reorientation of the organic ions with their alkyl chains pointing out of the aqueous surface. We ascribe this effect to ion paring between the charged functional groups on the respective organic ion and hydrophobic expulsion of the alkyl chains from the surface in combination with van der Waals interactions between the alkyl chains. These cooperative effects lead to a substantial surface enrichment of organic ions, with consequences for aerosol surface properties.
\end{abstract}

Atmospheric aerosol particles affect the global radiative balance, directly by scattering of sunlight, thus increasing Earth's albedo, and indirectly as a major source of cloud condensation nuclei. The net effect has been identified by the UN Intergovernmental Panel on Climate Change (IPCC) as the major uncertainty in climate models. ${ }^{1}$

In the atmosphere there are species of both natural and anthropogenic origin incorporated into aqueous aerosols. The aerosols can contain inorganic ions from the sea, organic compounds from both direct emissions and decomposition of biomaterial, soot from combustion, pollutants and mineral particles.

Depending on the environment, organic compounds constitute $20-90 \%$ of the submicron aerosol mass. ${ }^{2}$ Many atmospheric organic compounds are formed by reactions between primary hydrocarbon molecules and radicals resulting in the

\footnotetext{
${ }^{a}$ Dep. of Phys. \& Astron., Uppsala University, Box 516, SE-751 20 Uppsala, Sweden. E-mail: victor.ekholm@physics.uu.se

${ }^{b}$ Center for Free-Elec. Laser Sci., DESY, Notkestraße 85, DE-22607 Hamburg, Germany

${ }^{c}$ Dep. of App. Phys., Royal Inst. of Tech., Roslagstullsbacken 21, SE-114 21, Stockholm, Sweden

${ }^{d}$ Dep. of Cell \& Mol. Bio., Uppsala University, Box 596, SE-751 24 Uppsala, Sweden

${ }^{e}$ MAX IV Laboratory, Lund University, Box 118, SE-221 00 Lund, Sweden

$\dagger$ Electronic supplementary information (ESI) available: Analysis of experiential results regarding surface enrichments and orientation of the organic ions. There is also further analysis of the MD density profiles and RDFs on the same topics as well as the structure of the clusters. See DOI: $10.1039 / \mathrm{c} 8 \mathrm{cp} 04525 \mathrm{a}$
}

formation of e.g. carboxylic and amine groups, making them water-soluble seeds for cloud droplets. Most of the atmospheric organic aerosol are in fact formed through gas-to-particle conversion, resulting in so-called Secondary Organic Aerosols (SOA). The SOA consist of a multitude of compounds, ${ }^{3}$ including alkyl amines and carboxylic acids. Surface phenomena and processes are important for aerosols. First, the surface is where mass exchange with the environment, i.e. condensation and evaporation, takes place, and its surface tension is a key parameter in Köhler theory of water condensation into liquid droplets., 4 Second, the surface composition strongly affects the total aerosol composition over time as surface species are more exposed to incoming radicals and other gaseous compounds. In particular, some organic molecules have been shown to influence key surface phenomena and processes, such as surface tension, ${ }^{6,7}$ form hydrophobic surface layer that could strongly influence condensation and evaporation rates, ${ }^{8-11}$ as well as the chemical aging of the aerosol. ${ }^{12}$ Via aerosol growth and cloud condensation nuclei (CCN) activity, these effects in turn impact on the radiative forcing.

These processes have inspired investigations of the surface propensity of selected representative molecules in aqueous solutions. ${ }^{13-15}$ These investigations show that the surface composition generally differs from the bulk composition, both in terms of speciation and concentration. The surface enrichments can vary depending on species and conditions, and one to two orders of magnitude higher concentrations have been 
reported for relatively small organic compounds. ${ }^{16,17}$ Such composition differences between surface and bulk are, however, not generally taken into account in current climate models, which rather consider the surface to have the same composition as the bulk. The atmospheric science community is now beginning to recognize the need to include surface-bulk composition differences in climate models, ${ }^{18}$ making it crucial to improve our molecular level understanding of atmospheric surface phenomena and processes.

Atmospheric aerosols usually contain not only one species, and by using a model system containing a mixture of two organic species we are able to study a situation that is closer to the natural conditions than reported in studies so far. We have chosen an alkyl ammonium ion and a carboxylate ion, which both are important types of organic compounds in aerosols. The surface propensity of such a mixed organic solute solution is studied in comparison to the neat solutions using a combined experimental and theoretical approach to provide qualitative information on surface composition. We show that both organic ions are strongly surface enriched and that the mixture of the two exhibits even higher surface enrichment than the individual species. Lastly, we explore the microscopic mechanisms behind this cooperative effect.

\section{Methods}

\subsection{Experimental section}

The data was recorded at the undulator beamline I411 at MAX IV Laboratory, Lund, Sweden, ${ }^{19}$ using the surface and chemically sensitive X-ray Photoelectron Spectroscopy (XPS) in combination with a liquid jet. This well established technique has been described in detail previously. ${ }^{20}$ Shortly, the sample is introduced into the experimental chamber through a $20 \mu \mathrm{m}$ glass nozzle pushed by a HPLC pump and is exposed to the X-ray beam after about $1 \mathrm{~mm}$ downstream, depicted in Fig. 1b. The electron analyzer used was a Scienta R4000 mounted in $54.7^{\circ}$ (the so-called magic angle $)^{21}$ relative to the polarization plane of the synchrotron light and perpendicular to the liquid jet to cancel out angular emission effects. ${ }^{22}$ We assume that the equilibration times are fast enough to equilibrate the sample volume before it reaches the interaction zone; this has been discussed in ref. 15 . Two core levels have been probed, C 1s at $360 \mathrm{eV}$ photon energy and $\mathrm{N}$ 1s at $480 \mathrm{eV}$ photon energy giving electrons with kinetic energies at about 66-71 eV and 72-75 eV, respectively. According to the universal curve of mean free path, electrons with these kinetic energies will result in a surface sensitive measurement, with an effective attenuation length that is estimated to be about 5-10 $\AA^{23-25}$ We estimate the energy resolution based on the full width at half maximum of the gasphase $1 b_{1}$ peak to be about $0.40 \mathrm{eV}$, this includes experimental broadening. The precision of the binding energy peak positions is estimated to be in the order of $0.1 \mathrm{eV}$. The photoelectron signal is proportional to the abundance of the corresponding atom at the surface after normalization to the acquisition time and synchrotron ring current, which is a measure of the integrated photon flux.

$50 \mathrm{mM}$ LiBr solutions have been measured in direct succession of the experimental samples monitoring the signal stability by

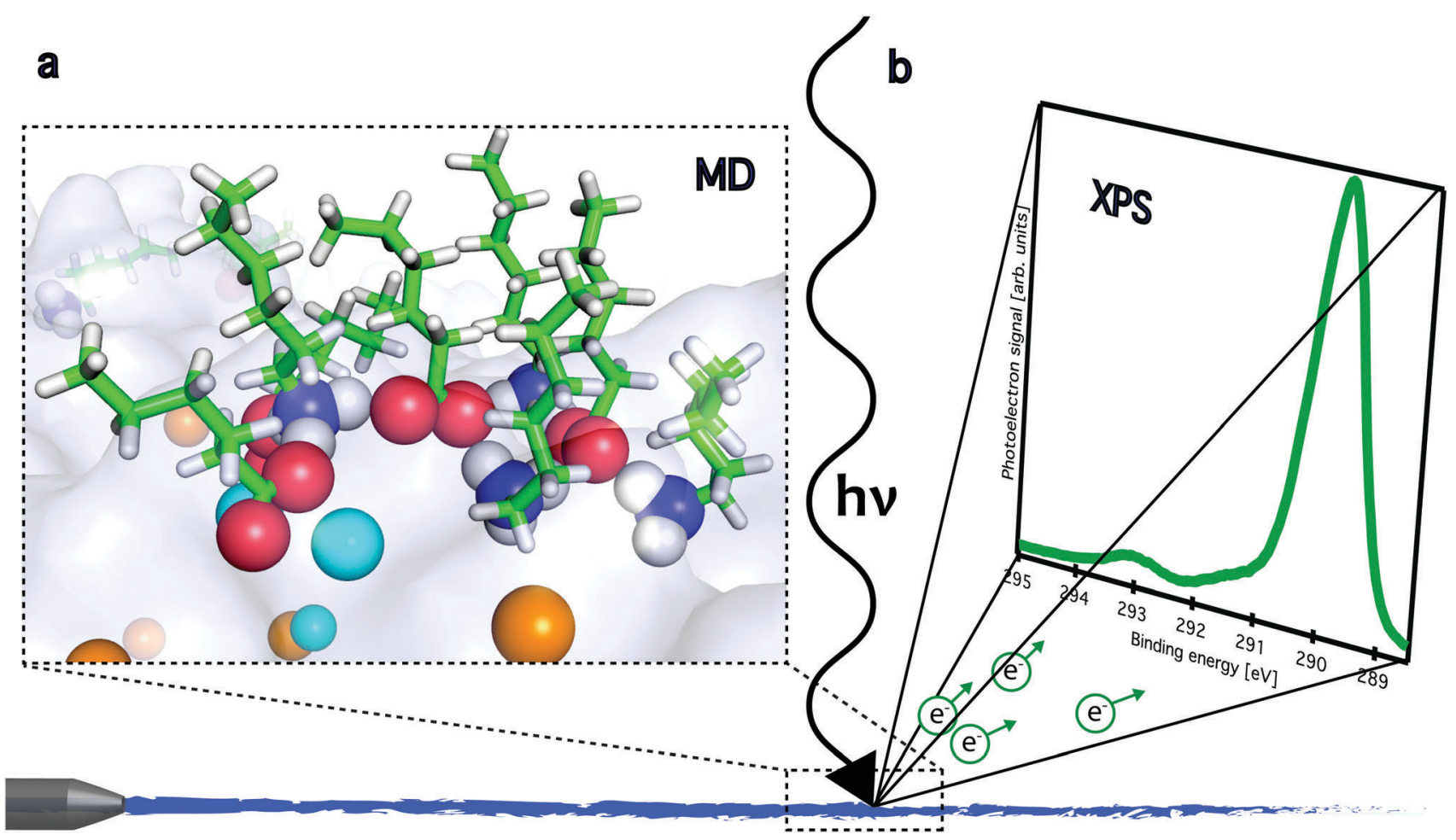

Fig. 1 (a) Schematic illustration of the liquid jet and a snapshot from the MD simulations of the mixed solution's surface showing ion pairing between the organics. In the MD-snapshot the atoms are illustrated as: carbon in green, hydrogen in white, oxygen in red, nitrogen in blue, sodium in light blue and chloride in orange. (b) Illustration of the acquisition of XPS data. 
Table 1 Solutions and their $\mathrm{pH}$ values

\begin{tabular}{ll}
\hline Solution & $\mathrm{pH}$ \\
\hline $100 \mathrm{mM}$ HexylammoniumCl & 7.6 \\
$100 \mathrm{mM}$ NaHexanoate & 7.4 \\
$50 \mathrm{mM}$ HexylammoniumCl & 7.4 \\
$+50 \mathrm{mM}$ NaHexanoate &
\end{tabular}

comparing the emission from the $1 b_{1}$ liquid water valence state. The small amount of salt in the stability measurement solution is added to increase the conductivity and reduce charging of the jet. ${ }^{26}$ The data have been energy calibrated to the $1 b_{1}$ liquid water valence state, positioned at $11.16 \mathrm{eV}^{27}$ and analyzed using IGOR Pro (WaveMetrics, Lake Oswego, OR) with the fitting procedure SPANCF. ${ }^{28}$ Voigt line profiles have been used for peak-fitting to accommodate for lifetime and experimental broadening.

All samples have been prepared with deionized water (18.2 $\mathrm{M} \Omega \mathrm{cm}$, Millipore Direct-Q), ultra sonicated and filtered (Whatman Puradisc Fp30 syringe filter with a pore size of $1.2 \mu \mathrm{m})$. All chemicals have been commercially bought with a nominal purity of at least $99 \%$. The hexylammonium solutions were produced starting from a hexylamine solution diluted with deionized water with the addition of $\mathrm{HCl}$ to lower the $\mathrm{pH}$ value to the target $\mathrm{pH}$ value, in this case a $\mathrm{pH}$ value of about 7.4 (Table 1). Water with the same $\mathrm{pH}$ value was added to the solution to reach the desired concentration. This was similarly done for the hexanoate solution, where $\mathrm{NaOH}$ was added to a hexanoic acid solution to reach the target $\mathrm{pH}$. Further, water was added with the same $\mathrm{pH}$ to reach the desired concentration. The mixed solute solution was produced by equal volumes from the two single solute $100 \mathrm{mM}$ solutions, giving roughly half the concentration of each species, i.e. $50 \mathrm{mM}$ sodium hexanoate $+50 \mathrm{mM}$ hexylammonium chloride. This is under the assumption that the density of the mixture is roughly the mean of the two single solute solutions. A portable Thermo Scientific $\mathrm{pH}$ meter was used during sample preparation, calibrated using buffer solutions at $\mathrm{pH} 4$ and 7 when measuring the $\mathrm{pH}$ of acidic samples and calibrated with buffer solutions of pH 7 and 10 when doing pH measurements for alkaline samples. To determine if the organic ions were surface enriched we compared the $\mathrm{C} 1 \mathrm{~s}$ intensity of the solutions to a $500 \mathrm{mM}$ sodium formate solution that was measured in direct succession. Since the formate ion is known to avoid the interface (see ref. 16, 29 and 30 ) it is possible by comparing intensities (after compensating for concentration differences and normalizing to the number of carbons per organic ion) to determine if the organic ion of interest is surface enriched.

\subsection{Molecular dynamics simulations}

For better insight in the dynamics of the ions at the water surface we have employed classical molecular dynamics (MD) simulations. Following earlier recipe $\mathrm{e}^{31-34}$ we used the GROMACS software toolkit. ${ }^{35}$ Molecular interaction parameters were based on the Generalized Amber force field (GAFF) ${ }^{36}$ in combination with the TIP3P water model. ${ }^{37}$ This combination of force field and water model has been shown to reproduce an important quantity in aqueous chemistry, the Gibbs energy of hydration, for propanoic acid and $n$-butylamine, which are similar to the molecules in this study. ${ }^{33}$ In an earlier MD study of pentanol in water solution, we observed that the GAFF/TIP3P gave similar results as the combination of force field OPLS/AA ${ }^{38}$ and SPC water model. ${ }^{39}$ This gives confidence that the results from the simulations are not force field dependent. Counter ions $\left(\mathrm{Na}^{+}\right.$and $\left.\mathrm{Cl}^{-}\right)$were also included in the simulation, and for those the common Amber force field parameters were used. ${ }^{40}$ The actual GAFF parameters were created using the Antechamber software, ${ }^{41}$ and the partial charges where determined using the RESP method. ${ }^{42}$ RESP is an integral part of the Antechamber package, which relies on either quantum calculations or, (as were used here) empirical methods, such as AM1-BCC, ${ }^{43,44}$ to provide the partial charges. Finally the topologies were then translated into the GROMACS format using the ACPYPE script. ${ }^{45}$ The set up of the simulation was done as follows: (i) the hexylammonium and/or the hexanoate ions together with inorganic ions, $\mathrm{Na}^{+}$and $\mathrm{Cl}^{-}$(acting as counter ions) were solvated in a $4 \mathrm{~nm} \times 4 \mathrm{~nm} \times 4 \mathrm{~nm}$ water box. (ii) An energy minimization simulation of the box was performed for 10 ps. (iii) The simulation box was elongated four times in one dimension to generate a liquid-vacuum interface. The final simulation box has the dimension $4 \mathrm{~nm} \times 4 \mathrm{~nm} \times 16 \mathrm{~nm}$. (vi) A 50 ps pre simulation was performed to equilibrate the system. (v) A final production run was performed, 20 ns. From the final $20 \mathrm{~ns}$ simulations the last $10 \mathrm{~ns}$ were used for analysis. To verify that the system was equilibrated we calculated the drift in the total energy for the part of the trajectory we used for analysis. All simulations showed a drift by less than $0.5 \mathrm{~kJ} \mathrm{~mol}^{-1}$, which can be compared to a standard deviation of around $350 \mathrm{~kJ} \mathrm{~mol}^{-1}$. This ensures an equilibrated system. The single solute solutions contained 54 organic ions with equal amounts of counter ions and 6624 water molecules, while the mixed solute solution contained 27 organic ions of each kind with equal amounts of counter ions and 6649 water molecules. We used a $1.1 \mathrm{~nm}$ cut-off both for the Lennard-Jones interactions and the distance where the direct Coulomb interactions were replaced by the particle mesh Ewald (PME) algorithm. ${ }^{46,47}$ To keep a constant temperature the Berendsen temperature coupling algorithm was used, with a coupling constant of $0.1 \mathrm{ps}^{48}$ The bonds were constrained using the LINCS algorithm, ${ }^{49}$ and periodic boundary conditions were applied in all simulations. The displayed density profiles were symmetrized.

\section{Results and discussion}

In this study we compare aqueous solutions of hexylammonium chloride $\left(\mathrm{HexNH}_{3}{ }^{+} \mathrm{Cl}^{-}\right)$and sodium hexanoate $\left(\mathrm{Na}^{+}\right.$ $\mathrm{HexOO}^{-}$) both by themselves and in mixture. In the following sections, we report and discuss the changes in surface concentration, orientation and arrangement of the two organic ions in the vapor-water interface upon mixing in comparison to the single solute solutions. 


\subsection{Surface enrichment and orientation}

In Fig. 2a, the $\mathrm{C} 1 \mathrm{~s}$ XPS spectra of $100 \mathrm{mM} \mathrm{HexNH}_{3} \mathrm{Cl}$ (blue dash-doted), $100 \mathrm{mM}$ NaHexOO (red dash double-doted), an artificial sum of the spectra from the two single solute solutions (green dashed) and the spectrum of the real mixed solute system of $50 \mathrm{mM} \mathrm{HexNH} \mathrm{H}_{3} \mathrm{Cl}+50 \mathrm{mM}$ NaHexOO (black solid) are depicted. Since the concentrations of the organic ions in the single solute systems are double that of the mixed solute system the artificial sum is divided by two for comparison.

Comparing the signal to noise ratio and intensity count numbers for these bulk concentrations to a $500 \mathrm{mM}$ sodium formate solution (as described in the Method section), both species are surface enriched in the single solute solutions, which is expected due to the hydrophobicity of the alkyl chains. If the two organic species would not affect each other in the mixed solute solution, the artificial sum and the real mixture would display similar intensities. Clearly, the signal from the real mixed solute solution is much stronger, i.e. that one or both of the organic ions are even more surface enriched in the mixed solute solution than in the single solute solutions. By analyzing the spectral components originating from the two organic species, $\mathrm{C}_{\mathrm{N}}, \mathrm{C}_{\mathrm{OO}}$ and $\mathrm{C}_{\mathrm{C}}$, and also considering the orientation of the organic ions one can see that both $\mathrm{HexNH}_{3}{ }^{+}$ and $\mathrm{HexOO}^{-}$are more enriched both in absolute terms and relative terms if normalizing to bulk concentration. Additionally, the orientation of one or both organic ions is such that the alkyl chains points out from the surface in the mixed solute solution. This is in contrast to the single solute solutions where the $\mathrm{HexNH}_{3}{ }^{+}$ions probably are laying flat on the surface while the alkyl chains of the $\mathrm{HexOO}^{-}$ions are pointing out. A detailed discussion of the surface enrichment and orientation is presented in the ESI. $t$

The increased surface enrichment of the mixed solute solution is also confirmed by the density profile from MD simulations displayed in Fig. 2c, where the organic ions accumulate on the surface with their alkyl chains pointing out. In other words, the bulk-surface equilibrium has shifted even more towards the surface as we mix the two surface-active organic compounds. The suggested mechanism behind the increased surface enrichment is ion pairing between $\mathrm{HexNH}_{3}{ }^{+}$and $\mathrm{HexOO}^{-}$ which leads to a rearrangement of the ions at the aqueous interface. The remaining part of this paper will explore this mechanism further.

\subsection{Ion pairing}

A strong indication of ion paring between the organic ions is seen in Fig. 2b where a binding energy difference of $0.36 \mathrm{eV}$ between the nitrogen 1s (N 1s) peak for the single $\mathrm{HexNH}_{3}{ }^{+}$ solution (blue solid) and the mixed $\mathrm{HexNH}_{3}{ }^{+}$solution (black dashed) is observed. The binding energy decrease is consistent with the presence of a negative charge in the proximity of the $-\mathrm{NH}_{3}{ }^{+}$headgroup in the mixed solution. Binding energy shifts related to contact ion pairing have been observed with XPS previously, though less strong (about $0.1 \mathrm{eV}$ ). ${ }^{50}$ The shift of $0.36 \mathrm{eV}$ indicates a stronger pairing of the ions investigated in this work. We can rule out that the shift originates from proton transfer, i.e. hexylamine, since such binding energy shift would be about $2.4 \mathrm{eV}$, see ESI. $\dagger$ Ion paring between the organic compounds is also observed in the radial distribution function (RDF) calculated from the MD simulations. In Fig. 3a three RDFs are presented from the mixed solution, between the nitrogen in $\mathrm{HexNH}_{3}{ }^{+}$and the two oxygens in $\mathrm{HexOO}^{-}$(red solid), between the terminal carbon of both molecules (black dashed) and oxygen-oxygen of water (blue dash-doted) as a reference. All RDFs are normalized to their maximum value for comparison. The RDF between the headgroups displays a sharp feature at about $2.8 \AA$ and a smaller, broader one at about 4-5 A. The first feature is interpreted as a well defined distance
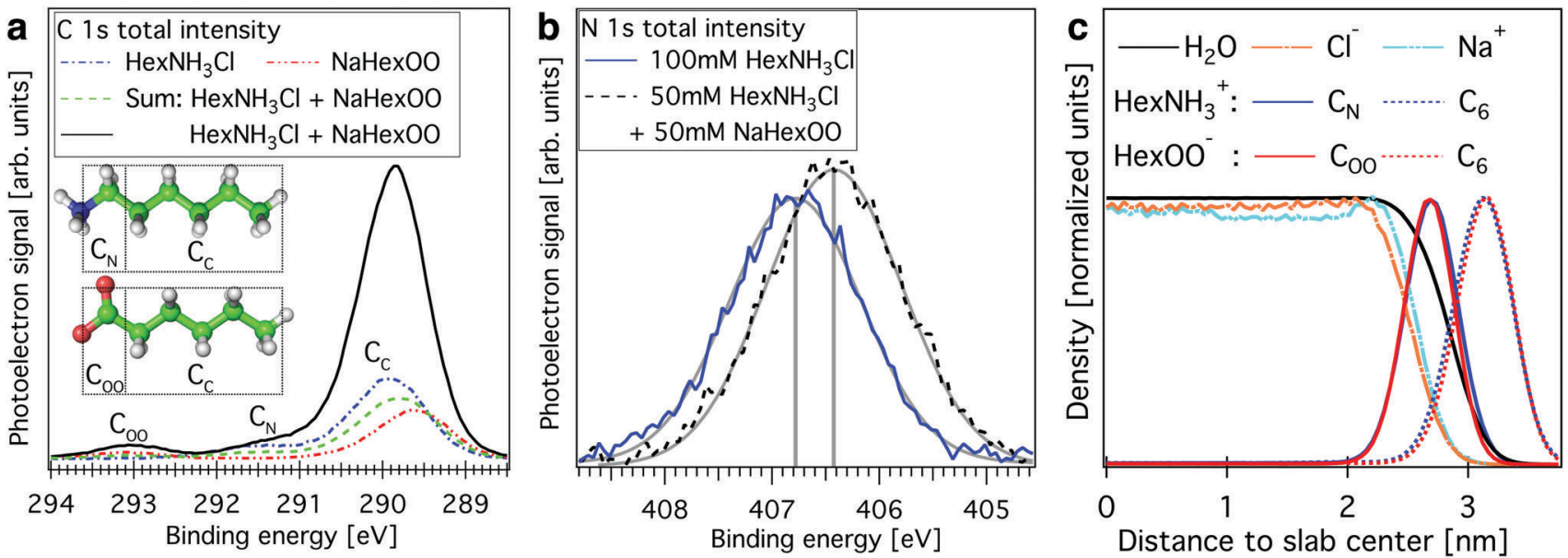

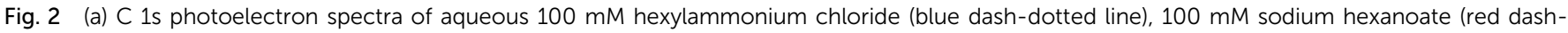

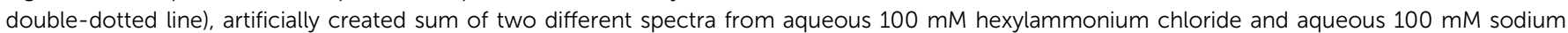

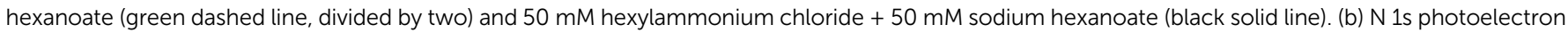

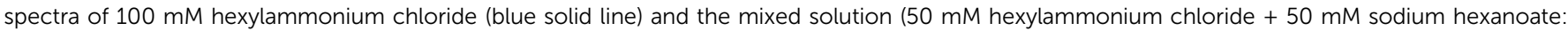

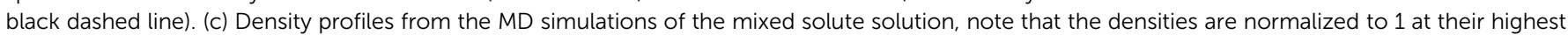
point in order to clearly display the positions of the ions at the surface. Also $\mathrm{C}_{6}$ in the label is the terminal carbon of the corresponding organic ion. 

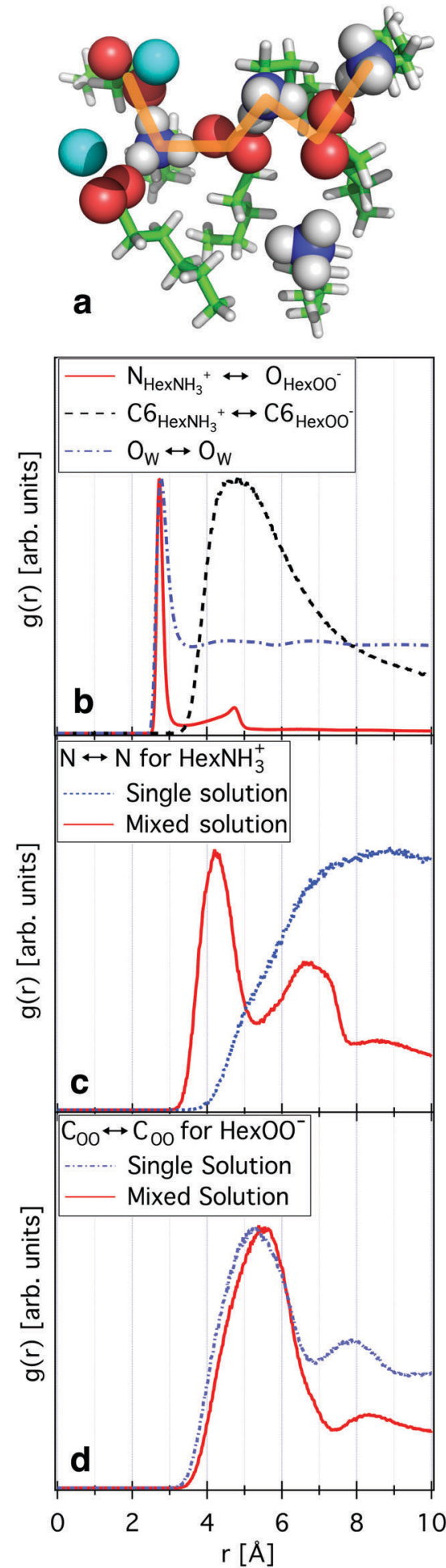

Fig. 3 (a) Snapshot of the same cluster as shown in Fig. 1(a) but from below illustrating how the structure of a cluster can look like. Note that the ions in teal bonding to $\mathrm{HexOO}^{-}$are sodium ions. (b) Radial distribution function of the nitrogen in $\mathrm{HexNH}_{3}{ }^{+}$and the oxygens in $\mathrm{HexOO}^{-}$plotted together with the RDF between the terminal carbon (C6) in $\mathrm{HexNH}_{3}{ }^{+}$and the terminal carbon (C6) in $\mathrm{HexOO}^{-}$and water-water as a reference; evaluated from the mixed solution. (c) Radial distribution function of the nitrogen-nitrogen distance both in the single and the mixed $\mathrm{HexNH}{ }_{3} \mathrm{Cl}$ solution. (d) Radial distribution function of the $\mathrm{C}_{\mathrm{OO}}$ to $\mathrm{C}_{\mathrm{OO}}$ distance both in the single and the mixed $\mathrm{NaHexOO}$ solution. between the $\mathrm{N}$ atom and the closest oxygen atom in $\mathrm{HexOO}^{-}$ and the second feature is interpreted as a less well defined but longer distance between the $\mathrm{N}$ atom and the second oxygen atom in $\mathrm{HexOO}^{-}$. Our simulations also suggest contact ion paring between the headgroups of $\mathrm{HexNH}_{3}{ }^{+}$and $\mathrm{HexOO}^{-}$as predicted from results of the experimental study. The RDF of the two terminal carbons displays a broad feature with its maximum at roughly $5 \AA$ meaning that while the charged groups have a well defined distance the alkyl chains are somewhat parallel and dangling back and forth with a higher degree of freedom at a longer distance than the distance between the headgroups.

\subsection{Clustering and cooperative effects}

In the MD snap shot in Fig. 1a the organic molecules do not form binary pairs at the surface but instead accumulate in larger clusters assembling into chain like structures with their alkyl chains pointing out of the surface. The same cluster is also shown from beneath the surface in Fig. 3a, note that the nearest neighbors of the organic ions are ions of opposite charge. The RDFs between the $\mathrm{C}_{\mathrm{OO}}$ carbons of $\mathrm{HexOO}^{-}$are displayed in Fig. 3d, for the single solute solution (blue dotted) and the mixed solute solution (red solid). In both solutions the $\mathrm{HexOO}^{-}$seems to have a similar correlation. It is possible that the counter ions $\left(\mathrm{Na}^{+}\right)$have a strong enough interaction with the $\mathrm{HexOO}^{-}$ions to counteract the Coulomb repulsion between the headgroups of $\mathrm{HexOO}^{-}$in the single solute solution. Similarly, the RDFs between the $\mathrm{N}$ atoms (in $\mathrm{HexNH}_{3}{ }^{+}$) both in the single solute solution and in the mixture are presented in Fig. 3c. The RDF of the single solute solution (blue dotted) shows an almost uniform distribution function from about $8 \AA$ and further away leveling out quickly, displaying no correlation. This is in contrast to the RDF of the mixed solution where there are several broad features at about $4.3 \AA$, $6.7 \AA$ and $8.5 \AA$. The $\mathrm{HexNH}_{3}{ }^{+}$ions are thus not only closer to each other in the mixture but they are also ordered.

This helps explaining the experimentally observed surface enrichment. In the single solute cases, the equally charged headgroups of the organic ions in the surface repel each other, which does not favor a high surface coverage of organic ions. In the mixed solute cases, however, the positive $\mathrm{HexNH}_{3}{ }^{+}$ions and the negative $\mathrm{HexOO}^{-}$ions are each other's counter ions, a cooperative effect which allows for a higher surface coverage of organic ions. The clusters have a net charge per ion close to zero, which is lower than the charge of the organic ions by themselves. It is then not unexpected that a system with less charge is more surface enriched than a system which otherwise is similar, due to the energy gained by the screening water. On top of the Coulomb interaction leading to an increased surface enrichment, the alkyl chains are relatively closely packed. With the alkyl chains pointing out of the surface, the organic ions also gain energy by van der Waals interaction between the chains instead of hydrogen-bonding with water. Both these effects add to the increased surface enrichment as the interactions are facilitated by the surface, we call this a cooperative effect. Similar cooperative van der Waals interactions leading to 


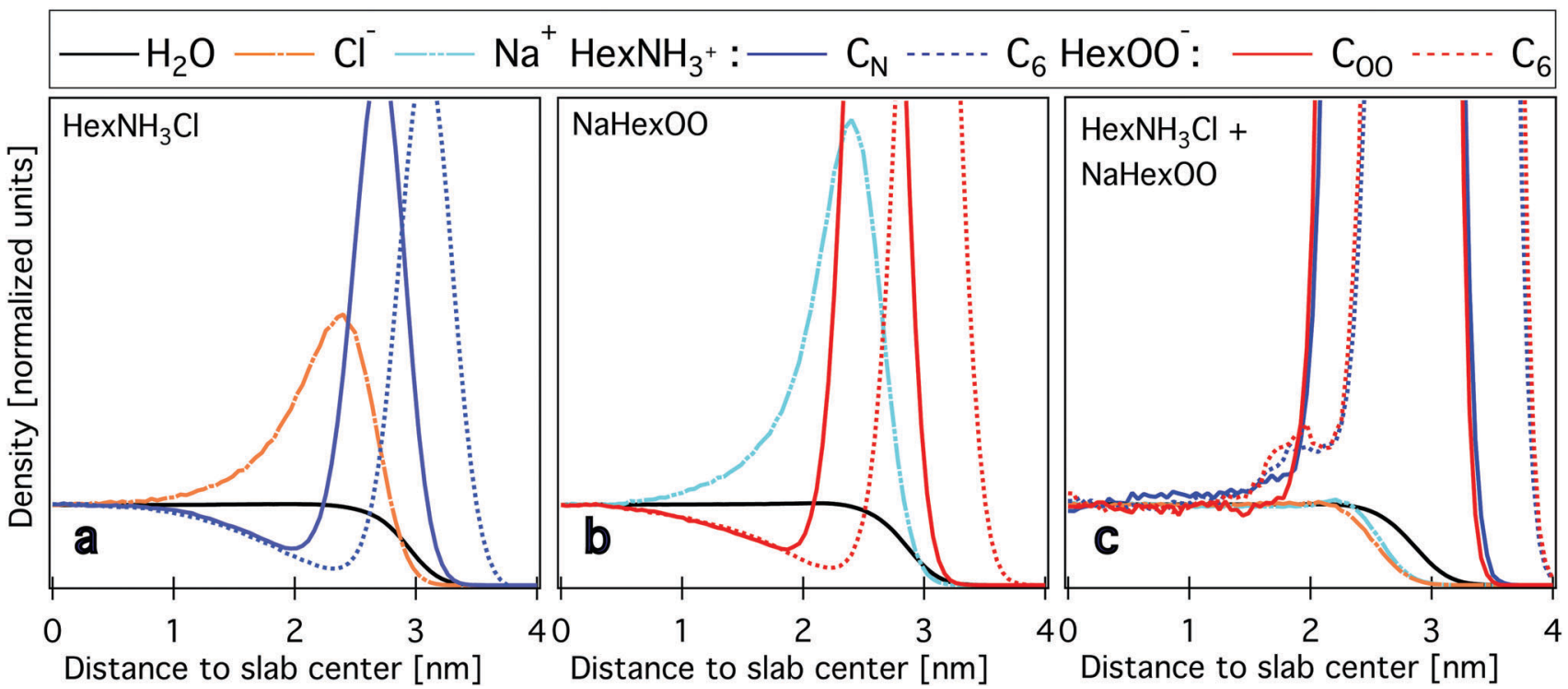

Fig. 4 The inorganic counter ions form a sublayer underneath the organic ions in the single solute solution (a and b) but not as pronounced as in the mixed solute solution (c). The organic ions are more surface enriched in the mixed solute solution (c), see ESI $\dagger$ for the same plots with different scale.

surface enrichment of alcohols have been observed previously, though the increased surface enrichment was not as high. ${ }^{16}$

With help of the MD simulations, we can also see how the surface layer changes in terms of the inorganic ions, as shown in Fig. 4. In the single solute solutions, panels Fig. $4 \mathrm{a}$ and $\mathrm{b}$ the inorganic ions act as counter ions to the surface-enriched organic ions. Together they form a structure resembling an electric double layer, with the organic ions at the surface and the inorganic ions in a sub-layer. Due to the strong surface enrichment of the organic ions, the inorganic ions are also strongly enriched in this sub-layer. In the mixed solute solutions, Fig. 4c, the inorganic ions do not act as counter ions to the organic ions, as the $\mathrm{HexNH}_{3}{ }^{+}$and $\mathrm{HexOO}^{-}$ions act as counter ions each other, as discussed above. The inorganic counter ions are therefore only slightly enriched in the sub-layer of the mixed solute solutions. The cooperative effects between the ions can thus lead to quite different surface structure and composition of both the surface and the immediate sub-layer.

\subsection{Conclusions}

Alkyl amines and carboxylic acids are important atmospheric organic compounds that exist in a wide range of $\mathrm{pH}$ values around 7 as organic ions. Using a combination of surfacesensitive XPS measurements and MD simulations, we have studied the surface composition of aqueous solutions of the atmospherically relevant organic compounds hexylammonium chloride and sodium hexanoate. Compared to solutions of the individual species, the mixed solution exhibits an increased surface enrichment of the organic ions, which we show to be due to the cooperative effect of ion-pairing between the two ionic species and the formation of zig-zag chains. This leads, already at low bulk concentrations, to clustering of the charged organic species at the air-water interface with the hydrophobic alkyl chains pointing towards the aerial side. This cooperative behavior on the microscopic scale thus leads to a much more organic-rich and hydrophobic surface than would be expected from the bulk composition. Furthermore, the specific cooperative effect in this study may affect atmospherically relevant surface properties and processes such as surface tension, condensation and evaporation rates, water accommodation and chemical aging of aerosols. Via aerosol growth and CCN activity, these microscopic surface phenomena have macroscopic effects on the radiative forcing. Our results demonstrate the importance of a detailed understanding of the surface composition of aqueous solutions that is one of the key factors to improve the modeling of aerosols in climate models.

\section{Conflicts of interest}

There are no conflicts to declare.

\section{Acknowledgements}

We thank Swedish Research Council (Grant 2013-3940 and 2014-04518) and the Helmholtz Association through the Center for Free-Electron Laser Science at Deutsches Elektronen-Synchrotron. MMW thanks the Carl Tryggers foundation for financing. MAX IV Laboratory, Lund, Sweden, is acknowledged for the allocation of beam-time and laboratory facilities.

\section{References}

1 T. Stocker, D. Qin, G. Plattner and M. Tignor, Climate Change 2013: The Physical Science Basis, Cambridge University Press, 2013.

2 J. L. Jimenez, et al., Science, 2009, 326, 1525-1529. 
3 A. H. Goldstein and I. E. Galbally, Environ. Sci. Technol., 2007, 41, 1514-1521.

4 H. Köhler, Trans. Faraday Soc., 1936, 32, 1152-1161.

5 R. Sorjamaa, B. Svenningsson, T. Raatikainen, S. Henning, M. Bilde and A. Laaksonen, Atmos. Chem. Phys., 2004, 4, 2107-2117.

6 N. Sareen, A. N. Schwier, T. L. Lathem, A. Nenes and V. F. McNeill, Proc. Natl. Acad. Sci. U. S. A., 2013, 110, 2723-2728.

7 J. Ovadnevaite, A. Zuend, A. Laaksonen, K. J. Sanchez, G. Roberts, D. Ceburnis, S. Decesari, M. Rinaldi, N. Hodas, M. C. Facchini, J. H. Seinfeld and C. O'Dowd, Nature, 2017, 546, 637-641.

8 J. F. Davies, R. E. H. Miles, A. E. Haddrell and J. P. Reid, Proc. Natl. Acad. Sci. U. S. A., 2013, 110, 8807-8812.

9 G. Ergin and S. Takahama, J. Phys. Chem. A, 2016, 120, 2885-2893.

10 R. E. H. Miles, J. F. Davies and J. P. Reid, Phys. Chem. Chem. Phys., 2016, 18, 19847-19858.

11 C. R. Ruehl, J. F. Davies and K. R. Wilson, Science, 2016, 351, 1447-1450.

12 M. Shiraiwa, M. Ammann, T. Koop and U. Pöschl, Proc. Natl. Acad. Sci. U. S. A., 2011, 108, 11003-11008.

13 N. L. Prisle, N. Ottosson, G. Öhrwall, J. Söderström, M. Dal Maso and O. Björneholm, Atmos. Chem. Phys., 2012, 12, 12227-12242.

14 N. Ottosson, E. Wernersson, J. Söderström, W. Pokapanich, S. Kaufmann, S. Svensson, I. Persson, G. Öhrwall and O. Björneholm, Phys. Chem. Chem. Phys., 2011, 13, 12261.

15 G. Öhrwall, N. L. Prisle, N. Ottosson, J. Werner, V. Ekholm, M.-M. Walz and O. Björneholm, J. Phys. Chem. B, 2015, 119, 4033-4040.

16 M.-M. Walz, J. Werner, V. Ekholm, N. L. Prisle, G. Öhrwall and O. Björneholm, Phys. Chem. Chem. Phys., 2016, 18, 6648-6656.

17 J. Werner, M. Dalirian, M. M. Walz, V. Ekholm, U. Wideqvist, S. J. Lowe, G. Öhrwall, I. Persson, I. Riipinen and O. Björneholm, Environ. Sci. Technol., 2016, 50, 7434-7442.

18 B. Noziere, Science, 2016, 351, 1396-1397.

19 M. Bässler, A. Ausmees, M. Jurvansuu, R. Feifel, J.-O. Forsell, P. de Tarso Fonseca, A. Kivimäki, S. Sundin, S. Sorensen, R. Nyholm, O. Björneholm, S. Aksela and S. Svensson, Nucl. Instrum. Methods Phys. Res., Sect. A, 2001, 469, 382-393.

20 H. Bergersen, R. R. T. Marinho, W. Pokapanich, A. Lindblad, O. Björneholm, L. J. Sæthre and G. Öhrwall, J. Phys.: Condens. Matter, 2007, 19, 326101.

21 J. Cooper, J. Chem. Phys., 1968, 48, 942.

22 S. Hüfner, Photoelectron Spectroscopy, Springer-Verlag, 1995.

23 C. Powell and A. Jablonski, Nucl. Instrum. Methods Phys. Res., Sect. A, 2009, 601, 54-65.

24 N. Ottosson, M. Faubel, S. E. Bradforth, P. Jungwirth and B. Winter, J. Electron Spectrosc. Relat. Phenom., 2010, 177, 60-70.

25 J. Werner, E. Wernersson, V. Ekholm, N. Ottosson, G. Öhrwall, J. Heyda, I. Persson, J. Söderström, P. Jungwirth and O. Björneholm, J. Phys. Chem. B, 2014, 118, 7119-7127.
26 B. Winter and M. Faubel, Chem. Rev., 2006, 106, 1176-1211. 27 B. Winter, R. Weber, W. Widdra, M. Dittmar, M. Faubel and I. V. Hertel, J. Phys. Chem. A, 2004, 108, 2625-2632.

28 Spectrum Analysis by Curve Fitting (SPANCF) macro package for Igor Pro by Edwin Kukk (edwin.kukk@utu.fi), University of Turku.

29 H. M. A. Rahman, G. Hefter and R. Buchner, J. Phys. Chem. B, 2012, 116, 314-323.

30 M.-T. Lee, F. Orlando, L. Artiglia, S. Chen and M. Ammann, J. Phys. Chem. A, 2016, 120, 9749-9758.

31 C. Caleman, P. J. van Maaren, M. Hong, J. S. Hub, L. T. Costa and D. van der Spoel, J. Chem. Theory Comput., 2012, 8, 61-74.

32 D. van der Spoel, P. J. van Maaren and C. Caleman, Bioinformatics, 2012, 28, 752-753.

33 J. S. Hub, C. Caleman and D. van der Spoel, Phys. Chem. Chem. Phys., 2012, 14, 9537-9545.

34 M.-M. Walz, C. Caleman, J. Werner, V. Ekholm, D. Lundberg, N. L. Prisle, G. Öhrwall and O. Björneholm, Phys. Chem. Chem. Phys., 2015, 17, 14036-14044.

35 B. Hess, C. Kutzner, D. van der Spoel and E. Lindahl, J. Chem. Theory Comput., 2008, 4, 435-447.

36 J. Wang, W. Wang, P. A. Kollman and D. A. Case, J. Mol. Graphics Modell., 2006, 25, 247260.

37 W. L. Jorgensen, J. Chandrasekhar, J. D. Madura, R. W. Impey and M. L. Klein, J. Chem. Phys., 1983, 79, 926-935.

38 W. L. Jorgensen and J. Tirado-Rives, Proc. Natl. Acad. Sci. U. S. A., 2005, 102, 6665-6670.

39 H. J. C. Berendsen, J. P. M. Postma, W. F. van Gunsteren and J. Hermans, in Intermolecular Forces, ed. B. Pullman, D. Reidel Publishing Company, Dordrecht, 1981, pp. 331-342.

40 J. Wang, R. M. Wolf, J. W. Caldwell, P. A. Kollman and D. A. Case, J. Comput. Chem., 2004, 25, 1157-1174.

41 J. Wang, W. Wang, P. A. Kollman and D. A. Case, J. Comput. Chem., 2005, 25, 1157-1174.

42 C. I. Bayly, P. Cieplak, W. D. Cornell and P. A. Kollman, J. Phys. Chem., 1993, 97, 10269-10280.

43 A. Jakalian, B. L. Bush, D. B. Jack and C. I. Bayly, J. Comput. Chem., 2000, 21, 132-146.

44 A. Jakalian, D. B. Jack and C. I. Bayly, J. Comput. Chem., 2002, 23, 1623-1641.

45 A. W. Sousa da Silva and W. F. Vranken, BMC Res. Notes, 2012, 5, 367.

46 T. Darden, D. York and L. Pedersen, J. Chem. Phys., 1993, 98, 10089-10092.

47 U. Essmann, L. Perera, M. L. Berkowitz, T. Darden, H. Lee and L. G. Pedersen, J. Chem. Phys., 1995, 103, 8577-8592.

48 H. J. C. Berendsen, J. P. M. Postma, A. DiNola and J. R. Haak, J. Chem. Phys., 1984, 81, 3684-3690.

49 B. Hess, H. Bekker, H. J. C. Berendsen and J. G. E. M. Fraaije, J. Comput. Chem., 1997, 18, 1463-1472.

50 V. Ekholm, M. Vazdar, P. E. Mason, E. Bialik, M.-M. Walz, G. Öhrwall, J. Werner, J.-E. Rubensson, P. Jungwirth and O. Björneholm, J. Chem. Phys., 2018, 148, 144508. 